\title{
STUDY ON THE ECOLOGICAL HEALTH EVALUATION OF A GEOPARK BASED ON DPSIR CONCEPTUAL MODEL - ILLUSTRATED BY THE QIANJIANG XIAONANHAI NATIONAL GEOPARK OF CHINA
}

\author{
ZHAO, Z. $.^{*}-\mathrm{LI}, \mathrm{P}^{1}{ }^{1}-\mathrm{YANG}, \mathrm{Y}^{1}-\mathrm{WU}, \mathrm{X}^{2}{ }^{2}-\mathrm{GUO}, \mathrm{Z}$. \\ ${ }^{1}$ Business School, Sichuan Agricultural University, Ya'an 611830, Sichuan, China \\ (phone: +86-135-4003-2565) \\ ${ }^{2}$ De Yi Cheng Li Environmental Engineering and Technology Ltd., Beijing, China \\ (phone: +86-187-2303-1677) \\ *Corresponding author \\ e-mail:602370810@qq.com; phone: +86-135-4003-2565 \\ (Received 22 $2^{\text {nd }}$ Feb 2018; accepted $24^{\text {th }}$ May 2018)
}

\begin{abstract}
With the rapid development of science tourism, geoparks are brought into focus of many geologists and tourists because there are of high scientific values for experts and we can disseminate science to the public. In recent years, there have been many problems in the construction of geoparks in China. The quick demand growth of geoparks conflicts with the ecological health of the area prominently. It is of great significance for ameliorating the planning and improving the development potential of a geopark and evaluate the ecological health of a geopark by combining qualitative and quantitative indicators. Illustrated by the example of Xiaonanhai National Geopark in Qianjiang, Chongqing and based on the theory of ecological health, this paper constructs the eco-health evaluation system for geological parks through DPSIR conceptual model. We use entropy and multi-level fuzzy synthesis evaluation method to determine the factor's proportion and calculate Geopark Ecological Health Index. The result shows that the highest score of Qianjiang Xiaonanhai Geopark is 0.6643, and the lowest score is 0.6120 . Though the score reveals a general trend of increase, the gap between scores of indicators is large. Based on the conclusion, some countermeasures and suggestions to improve the eco-construction and management planning of Qiannan XiaonanHai National Geopark are put forward.
\end{abstract}

Keywords: Qiannan Xiaonanhai National Geopark, health degree, index evaluation system, DPSIR conceptual model, fuzzy comprehensive evaluation

\section{Introduction}

Geopark is a new name created by UNESCO in the study on the feasibility of the Geoparks Project. According to the definition of geoparks by the Ministry of Land and Resources of the People's Republic of China No. 77 (2000), geoparks should be relic resources with special scientific value, popular science education value, and aesthetic value at the national and even international levels. It is necessary to provide geological records that can present important geological evidence for a certain geological event or stage in a certain area, and have special geological features, fossils, or geological relics with typical geomorphological meaning.

In other countries, some research studies have already been conducted on geoparks in the past. In 1999, UNESCO officially launched the World Geopark Program. Italian studies expounded the scientific and educational importance about geological remains of soil profiles, tourism and recreational value, and demonstrated that the protection of geological sites could be better achieved through the implementation of geographic databases (Edoardo and Costantini, 1986). Researchers studied two cities and towns in 
the United States that carried out geological tourism and elaborated on its unique practices including the key points of geological tourism cooperation, social promotion, education innovation, and field discipline (Wandersee and Clary, 2005). The concept of geoscience tourism is likened to the three dimensions of a box, metaphorically referring to shapes, processes and tourism.

However, the research on geoparks in China started late, but in recent years, more research has been done on the geoparks. Characteristics of geological tourism were analyzed in the United States National Park, focusing on the study of the protection of geological landscapes, eco-system, resource and environment in the United States National Park while conducting tourism activities and thinking that it is of siginificant reference for China (Xie and Liu, 2003). The protection status of Wudalianchi Global Geopark was analyzed and the sustainable development model was studied. The proposed elements of the model were the followings: leading community residents to participate in tourism development, strengthening the legislative system, reforming the geopark management system, establishing an information base, creating a network of geological relics and training specialized management personnel (Qian and Zhao, 2006). Scholars at home and abroad mainly focused on the development, construction, and problems of geoparks, discussed and studied the types and protection of geological relics, geoparks, and tourism economy. In response to the initiative of UNESCO to establish the "Global Geopark Network System", the Ministry of Land and Natural Resources, which are in charge of the declaration, approval and construction of geoparks as well as the formulation of the relevant laws, regulations and policies of geoparks, officially launched the plan of China's national geopark construction in 2000. After more than 10 years of development, China has become a geopark power in quantity.

Geoparks not only provide a public place for scientific sightseeing, leisure, health care, public education, cultural and entertainment, but also bring great social and economic benefits because of its irreproducibility as geological landscape, cultural landscapes and ecological focus protected areas, which has great scientific research value.

Tourism industry used to be considered as a "smoke-free industry" and would not cause environmental problems ( $\mathrm{Li}, 2012)$. However, with the continuous development of society and economy, the contradiction between tourism development and ecological protection has become increasingly prominent. The contradiction between the social and economic benefits and ecological and environmental benefits has become the major problem that geoparks face on the way of sustainable development. At present, the protection of the ecology and environment has become a hot topic in the field of academic research. The earliest health degree which was used to measure the health of the human body from multiple dimensions such as body, spirit, and society, gradually extended to other disciplines, which means a quantitative measurement of the health level of an industry or an experimental site. The research methods were mostly based on the characteristics of a certain industry and the index systems of evaluation were constructed based on the actual situation of the industry. Then the industry's health degree was evaluated, as an important indicator to measure socio-economic and ecological environmental benefits of the scenic area (Wang, 2016). Health degree is becoming more and more important in the field of ecological health.

Taijin was took as an example to establish an index system of urban ecosystem health assessment considering the aspects of vitality, organizational structure, resilience, 
ecosystem service function, and population health of the urban ecosystem (Zhao et al., 2013). The basic principles and methods of regional ecosystem health assessment were explored in the aspects of regional types, target units, model methods, selection of indicators, thresholds, and weight settings (Peng et al., 2007). The "pressure-stateresponse" (PSR) framework model was applied to establish an indicator system and constructed evaluation model for the ecosystem health assessment of river basins (Yan et al., 2008).

Nowadays, although some academic achievements have involved the evaluation of ecosystem health and various indicators of the tourism industry, the overall quantity is small and the comprehensiveness is inadequate. Moreover, index systems in the aspect of evaluation for the health of geoparks are rarely used. Constructing a health evaluation index system suitable for geological parks means a conceptual model for measuring and evaluating environmental and sustainable health development. It analyzes the interaction between human and environmental systems from a systemic perspective, and comprehensively analyzes and describes environmental problems and their common models for social development. It is divided into driving forces (D) indicators, pressure (P) indicators, status (S) indicators, impact (I) indicators and response (R) indicators (Qin and Lu, 2014). Evaluating the overall health of the geoparks is a new area that needs to be researched and developed urgently in the tourism industry and those research are of high innovativeness and practical value.

Based on the field investigation of the socio-economic development and ecoenvironmental protection of Qianjiang Xiaonanhai Geopark, this paper starts with the concept of health degree of tourism industry, and selects the factors that have an important influence on the eco-health of the geopark as evaluation indices. We construct the evaluation index system of eco-health of geoparks through DPSIR conceptual model, and use fuzzy comprehensive evaluation method to calculate each factor and overall health index of Qianjiang Xiaonanhai Geopark, in order to analyze the connotation of ecological health of Xiaonanhai Geopark and its significance provides a theoretical basis and references for its declaration of the world-class geopark, to promote its scientific planning, rational construction and sustainable development. At the same time, this paper tries to build a business-ecosystem assessment system suitable for geoparks, promote the development of standardized, rationalized, scientific and sustainable geoparks, and propose measures and advice for integrating internal and external resources and optimizing current development models in order to increase their efficiency, so as to make due contributions to local economic development.

\section{Materials and Methods}

\section{The overview of the research area}

Qianjiang Xiaonanhai National Geological Park is located in the Qianjiang District, Chongqing, the junction of Chongqing and Hubei province (east longitude $108^{\circ} 38^{\prime} 20^{\prime \prime}$-$108^{\circ} 49^{\prime} 48^{\prime \prime}$, north latitude $\left.29^{\circ} 31^{\prime} 14^{\prime \prime}--29^{\circ} 43^{\prime} 27^{\prime \prime}\right)$. It is 32 kilometres north of the county seat, covers an area of about 30 square kilometres. On the June 10, 1856, a 6.25magnitude earthquake with an intensity of $8^{\circ}$ on the ground cut off rivers and blocked the lake, creating the magnificent landscape for the complete ancient earthquake ruins. Dakuayan and Xiaokuayan in the north, two precipices, and other relics remain clearly visible. The place is rich in multi-type geological resources. As a national geopark, Xiaonanhai is a non-renewable and non-replicable landscape with a high value of both 
science popularization for public and scientific research for experts and scholars. It can provide sightseeing, leisure and other tourist activities with scientific education. Figure 1 shows the research site.

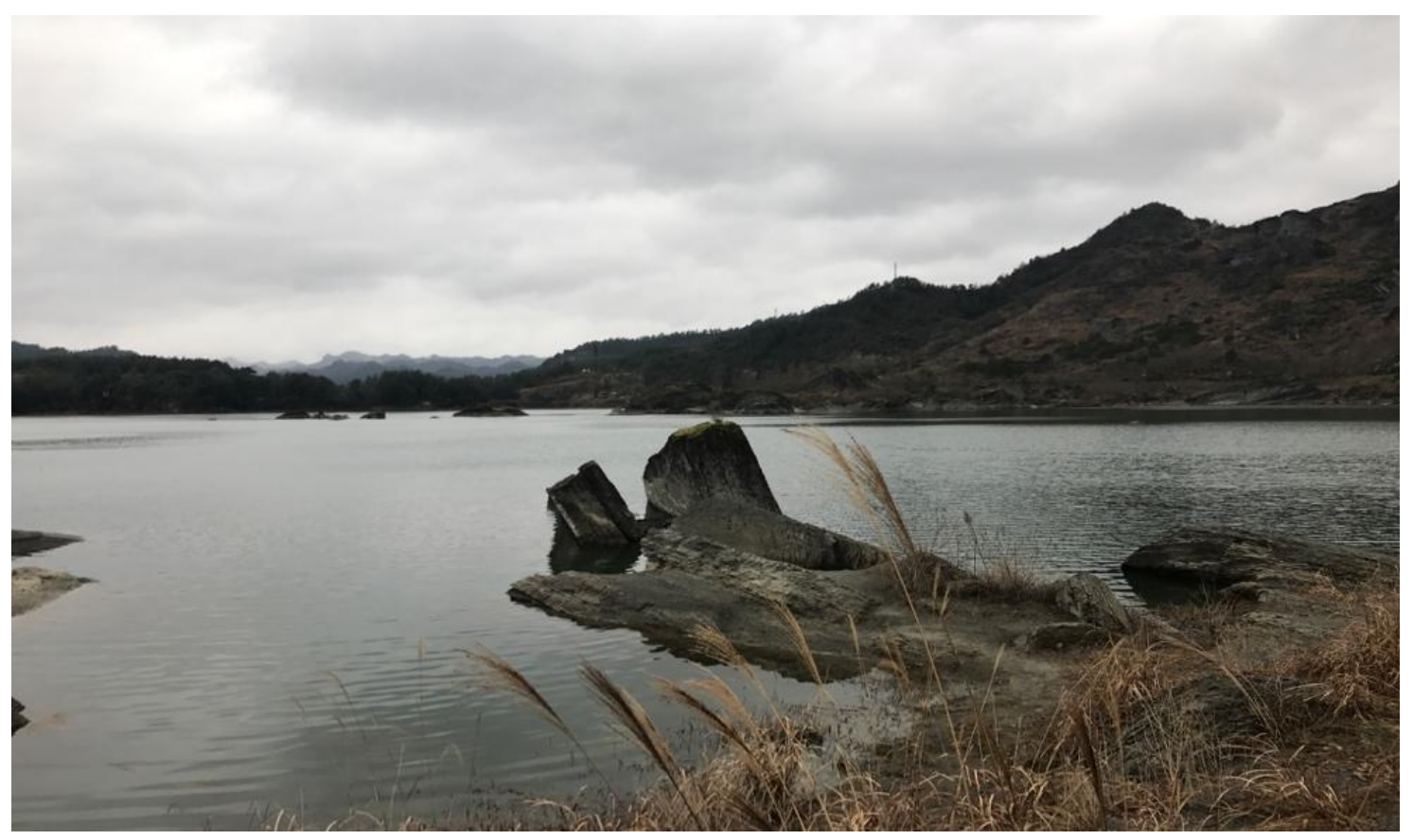

Figure 1. The experimental site of Qianjiang Xiaonanhai National Geopark

\section{Qianjiang Xiao Nanhai scenic area health evaluation index content}

\section{Driving force indicators}

According to the explanation of the driving force in DPSIR model, the "driving force" in the evaluation of the health of geoparks is the potential cause of environmental change. It can be divided into two categories: natural driving force and socio-economic driving force. The natural driving force mainly includes climate change and natural disasters. Their impact on the geoparks often take a long time to emerge. The landscape of Qianjiang Xiaonanhai Geopark is relatively stable, and the aim of evaluation is the current situation, so the driving force indicator here mainly refers to the socio-economic driving force. Socio-economic driving force includes population growth, tourism demand (number) growth, GDP growth and other factors. Population growth can easily lead to encroachment on landscape land. Economic growth has a direct impact on scenic spots development.

\section{Pressure indicators}

The pressure on geoparks is mainly caused by the contradiction between the everincreasing demand for tourism and the irreproducibility and expansibility of geological landscape resources. Compared with other industries, tourism industry tend to be more vulnerable and often face the threat of being constantly weakened. The population density, regional development index, utilization of tourist space and environmental 
carrying capacity are chosen to reflect the pressure on natural environment of geoparks caused by human activities.

\section{State indicators}

Geopark health status is the result of the driving force and pressure. The status and dynamic changes of the geoparks eco-environment are the basis of the health degree analyses of geoparks. The eco-system can be mainly refelected by the vegetation, biology, air quality, surface water quality and landscape state. When selecting natural state indicators, forest coverage, biodiversity, negative oxygen ion content, landscape fragmentation, surface water quality, comprehensive air pollution index can be selected to describe the eco-system status of Qianjiang Xiaonanhai Geopark comprehensively. In terms of social and economic status, the level of tourists' consumption is chosen as the representative to reflect attractiveness.

\section{Impact indicators}

Impact indicators are related to human health and life closely. The changing health level in tourist area will in turn have an impact on many aspects of human life quality, health, socio-economic structure and so on. The impact indicators of the DPSIR model of Qianjiang Xiaonanhai Geopark is used to describe the final social and economic effect when the health degree of the geopark change. Its impact on society and economy is mainly reflected in the change of visibility of tourist areas abroad, the satisfaction of tourists, total tourism revenue, economic growth and people's living standards. Common indicators reflecting these changes include area visibility, tourist satisfaction, tourist period, GDP per capita and so on.

\section{Response indicators}

The pressure is caused by socio-economic and natural factors which shaped current status of geoparks. The current status, in turn, affects the scenic area development potential and direction in the future and affects the scenic economic belt. Therefore, a corresponding social response must be made. People tend to promote the sustainable development of geoparks by adopting active countermeasures and policies such as improving resource utilization efficiency, reducing pollution and increasing investment in environmental protection. Therefore, choosing the ratio of environmental protection input to GDP, infrastructure construction in tourist areas, improvement of laws and regulations reflects the human's guiding role in the process of sustainable development of the park.

\section{Evaluation methods}

The Qianjiang Xiaonanhai tourist spot is a complex ecosystem. There are many indicators involved in ecosystem health assessment and the ambiguities are difficult to determine. Therefore, the entropy method is adopted to get the weight of each evaluation indicators, and the multi-level fuzzy comprehensive evaluation method is adopted to calculate the geology park health index.

\section{Evaluation system construction}

The ecological health system of Qianjiang Xiaonanhai National Geological Park is typical and complex. It is a growing giant system with multilevel. For the giant 
multivariable system, we use the description of state variables to reflect its inherent laws. According to the principle of representativeness, the selection of indicators was based on a large number of the results of previous literature and studies (Qin et al., 2013). Based on the "Driving Force-Pressure-State-Influence-Response" (DPSIR) model, an assessment index system of ecosystem health in Qianjiang Xiaonanhai Geopark was constructed. According to the actual situation of Qianjiang Xiaonanhai Geopark, 22 evaluation indices were selected, including 3 driving force indicators, 4 stress indicators, 7 state indicators, 5 impact indicators and 3 response indicators (Table 1).

\section{The source of evaluation indicators}

The research data are mainly from "Qianjiang 2012-2016 National Economic and Social Development Bulletin", "Chongqing Province Statistical Yearbook", "Qianjiang Yearbook", public data of Qianjiang District Protection Bureau of Chongqing Municipality, field investigation of Qianjiang Xiaonanhai Geopark, and from the principal office of the park.

\section{Determine the indicators weight}

The weight of eco-health evaluation index in tourist area is to empower the evaluation index relative to the importance of eco-health in scenic area to distinguish its contribution size. Determining the weight of an evaluation indicator is a very important element that directly affects the outcome of the evaluation.

The method of determining the index weight can be divided into two major categories: subjective weighting and objective weighting. Among them, the subjective empowerment method mainly based on expert advice and experience, such as expert scoring method, analytic hierarchy process, etc., objective empowerment is calculated by certain mathematical methods, such as principal component analysis, mean square error, the coefficient of variation method (Zhu et al., 2012). In this paper, according to the actual situation of ecological indicators in Xiaonanhai Geopark, in order to minimize the limitation of weight calculation, entropy weight method was used to empower each evaluation index of Xiaonanhai Geopark. In a specific operation, entropy weight method was based on the degree of variation of each index, then the entropy of each index was calculated, and the weight of each index was corrected through the entropy so as to obtain more objective and scientific index weight. Based on the data of health degree of Qianjiang Xiaonanhai Geopark from 2012 to 2016, the objective weight is determined according to the basic idea of entropy weight method, the size of index variability. In the comprehensive evaluation, the smaller information entropy of an index indicates the greater difference between the index values, the more relevant information provided, the more important role an index plays in the comprehensive analysis and evaluation, and thus the greater weight it should have; and vice versa (Shi and Chen, 2015).

Before evaluating, the data needs to be dimensioned before the metrics are empowered. In order to get a more objective weight, in this study, the objective weight of the indicator is calculated by the entropy method, and the calculation principle of the entropy method are as follows (Zhu, 2014): 
1) Each indicator's dimensions and units are different and cannot be directly compared and calculated. Therefore, before each indicator's weight is calculated, it needs to be standardized:

When the indicator is a positive indicator, the standardization formula is:

$$
x_{i j}^{\prime}=\frac{x_{i j}-x_{j}^{\min }}{x_{j}^{\max }-x_{j}^{\min }}
$$

When the indicator is a negative indicator, the standardization formula is:

$$
x_{i j}^{\prime}=\frac{x_{j}^{\max }-x_{i j}}{x_{j}^{\max }-x_{j}^{\min }}
$$

2) In order to eliminate the negative value of the translation process, after some standard values are normalized, there may be small or negative values. For normalization and convenience of calculation, the normalized values are shifted to eliminate the above situation.

$$
x_{i j}^{\prime}=H+x_{i j}^{\prime}
$$

where $\mathrm{H}$ is the magnitude of the index shift, generally takeing 1.

3) The dimensionless process of the original data:

$$
y_{i j}=\frac{x_{i j}^{\prime}}{\sum_{i=1}^{n} x_{i j}^{\prime}}
$$

4) The entropy of each index is calculated as follows:

$$
e_{j}=-\frac{1}{\ln n} \sum_{i=1}^{n} y_{i j} \ln y_{i j}
$$

5) The difference coefficient of the first index is calculated as follows:

$$
g_{j}=1-e_{j}
$$

(Among them, $j=1,2$, the index number is $p$ ).

6) The weight of the first indicator is calculated as follows: 


$$
\omega_{j}=\frac{g_{j}}{\sum_{j=1}^{p} g_{j}}
$$

(Among them, $\mathrm{j}=1,2$, the index number is $p$ ).

Table 1. shows the the weights of indicators.

Table 1. Qianjiang Xiaonanhai Geopark ecosystem health

\begin{tabular}{|c|c|c|c|c|}
\hline $\begin{array}{l}\text { Object } \\
\text { Layer }\end{array}$ & Criterion Layer & Indicator Layer & Weights & $\begin{array}{c}\text { Tendenc } \\
\mathbf{y}\end{array}$ \\
\hline \multirow{22}{*}{$\begin{array}{l}\text { Qianjiang } \\
\text { Xiaonanhai } \\
\text { Geopark } \\
\text { ecological } \\
\text { health } \\
\text { index } \\
\text { system }\end{array}$} & \multirow{3}{*}{$\begin{array}{l}\text { Driving force } \\
\qquad \text { ( D ) }\end{array}$} & Natural population growth rate (D1) & 0.0391 & - \\
\hline & & Tourist growth rate (D2) & 0.0457 & + \\
\hline & & GDP growth rate (D3) & 0.0417 & + \\
\hline & \multirow{4}{*}{$\begin{array}{c}\text { Pressure } \\
\text { ( P ) }\end{array}$} & Population density (P1) & 0.0402 & - \\
\hline & & Regional Development Index (P2) & 0.0366 & - \\
\hline & & $\begin{array}{l}\text { Visitor space utilization concentration } \\
\qquad(\mathrm{P} 3)\end{array}$ & 0.0311 & - \\
\hline & & Natural disaster days (P4) & 0.0324 & - \\
\hline & \multirow{7}{*}{$\begin{array}{l}\text { Status } \\
(\mathrm{S})\end{array}$} & Forest Coverage $(\mathrm{S} 1)$ & 0.0375 & + \\
\hline & & Biodiversity (S2) & 0.0387 & + \\
\hline & & $\begin{array}{l}\text { Tourism per capita consumption level } \\
\qquad(\mathrm{S} 3)\end{array}$ & 0.0487 & + \\
\hline & & Negative oxygen ion content (S4) & 0.0356 & + \\
\hline & & Landscape fragmentation (S5) & 0.0521 & - \\
\hline & & Surface water quality（S6） & 0.0684 & + \\
\hline & & Air Pollution Index (S7) & 0.0393 & - \\
\hline & \multirow{5}{*}{$\begin{array}{l}\text { influences } \\
\qquad(\mathrm{I})\end{array}$} & Tourist area visibility (I1) & 0.0414 & + \\
\hline & & Tourist satisfaction (I2) & 0.0818 & + \\
\hline & & Suitable period (I3) & 0.0345 & + \\
\hline & & $\begin{array}{l}\text { Total tourism revenue and GDP ratio } \\
\text { (I4) }\end{array}$ & 0.0485 & + \\
\hline & & Per capita GDP (I5) & 0.0358 & + \\
\hline & \multirow{3}{*}{$\begin{array}{l}\text { response } \\
(\mathrm{R})\end{array}$} & $\begin{array}{l}\text { The proportion of environmental } \\
\text { protection in GDP ( R1) }\end{array}$ & 0.0466 & + \\
\hline & & $\begin{array}{l}\text { Tourism infrastructure intact rate } \\
(\mathrm{R} 2)\end{array}$ & 0.0424 & + \\
\hline & & $\begin{array}{l}\text { Improvement of laws and regulations } \\
\text { (R3) }\end{array}$ & 0.0818 & + \\
\hline
\end{tabular}

"+" stands for positive indicators, "-" stands for negative indicators

According to the relationship between indicators and ecological health, we divided Qianjiang Xiao Nanhai scenic ecological health assessment indicators into two categories: 
1) Positive indicator. The index is positively correlated with the degree of ecological health (positive index). The higher the index is, the higher the degree of ecological health will be. These indicators are e.g.: GDP growth rate, biodiversity and forest coverage indicators.

2) Negative indicator. The index is negatively correlated with the degree of ecological health (negative index), the higher the index is, the lower the degree of ecological health will be. These indicators are e.g.: the natural population growth rate, air pollution index.

\section{Evaluation criteria}

After confirming indicators and evaluation methods of Xiaonanhai Scenic Spot, the determination of each indicator was essential, which was the key to health degree assessment. The standard value (or reference value) of eco-system health evaluation of geoparks is constantly changing. The evaluation criteria of this study are mainly referring to the international, national, industrial and local standards, and the relevant standards in previous literature. According to the background and target value of the local tourism area, the ecological system of Xiaonanhai Geopark is divided into five subtypes: morbid (0.0-0.2), generally morbid (0.2-0.4), sub-healthy (0.4-0.6), healthy (0.6- 0.8$)$, very healthy $(0.8 \sim 1.0)$. Table 2 shows the health rating and content of geopark.

Table 2. Geological park ecological health rating and content

\begin{tabular}{c|c|c|c|c|c}
\hline Rating level & Very healthy & Healthy & Sub - healthy & General morbid & Morbid \\
\hline $\begin{array}{c}\text { Normalized } \\
\text { Value }\end{array}$ & $0.8 \sim 1.0$ & $0.6 \sim 0.8$ & $0.4 \sim 0.6$ & $0.2 \sim 0.4$ & $0 \sim 0.2$ \\
\hline
\end{tabular}

\section{The Evaluation of established model}

Fuzzy comprehensive evaluation method combines qualitative and quantitative analysis, unifies accuracy and inaccuracy, and integrates multiple factors (Zhu et al., 2012). The mechanisms and factors that affect the eco-health of tourism areas are very complicated. There are many things and factors that have ambiguous properties ( $\mathrm{Li}$, 2012). The interaction between them and the influence of each factor on system function are hard to accurately measure in terms of quantity. Therefore, in this paper, fuzzy comprehensive evaluation method is used to calculate the health index of Qianjiang Xiaonanhai Geopark, so as to scientifically evaluate the health status of its ecosystem.

\section{Establish evaluation set}

It is assumed that the fuzzy evaluation result of the evaluation index of the geologic park health degree is $\mathrm{V}$. The evaluation grades are divided into morbid, generally morbid, sub-healthy, healthy and very healthy. The five rating criteria are set to s1, s2, s3, s4, s5. The standard value of each indicator and standard source have been described above. Constructed fuzzy evaluation sets $\mathrm{V}$ is:

$\mathrm{V}=\{\mathrm{v} 1, \mathrm{v} 2, \mathrm{v} 3, \mathrm{v} 4, \mathrm{v} 5\}=\{$ disease, general morbid, sub-healthy, healthy, very healthy . 


\section{Determine membership function}

Membership function has various forms. The determination of the membership function was based on the nature of the evaluation index. General evaluation indices can be divided into two categories: positive (or inverse) and moderate indicators. For the positive (or inverse) index, the greater the value (or smaller), the better; for the moderate index, it is a better value when it is in the satisfactory range. The farther away from this interval, the worse its evaluation status will be (Yue and Liu, 2008):

1) The membership function of positive index

According to the analysis of geology park health evaluation of the reality and evaluation purposes, ascending trapezoidal distribution function and linear triangular function can be used for the positive index membership function. The results are as follows:

$$
\begin{aligned}
& y_{D 1}(x)=\left\{\begin{array}{rl}
0 & x \geq s_{2} \\
\frac{s_{2}-x}{s_{2}-s_{1}} & s_{1}<x<s_{2} \\
1 & x \leq s_{1}
\end{array}\right. \\
& y_{D 2}(x)=\left\{\begin{array}{cc}
0 \quad x \leq S_{1} \text { or } x \geq s_{3} \\
\frac{X-s_{1}}{S_{2}-s_{1}} & S_{1}<x \leq s_{2} \\
\frac{s_{3}-x}{s_{3}-s_{2}} & S_{2}<x<s_{3}
\end{array}\right. \\
& y_{D 3}(x)=\left\{\begin{array}{cc}
0 \quad x \leq S_{2} \text { or } x \geq S_{4} \\
\frac{x-S_{2}}{S_{3}-S_{2}} & S_{2}<x<S_{3} \\
\frac{S_{4}-x}{S_{4}-S_{3}} & S_{3} \leq x<S_{4}
\end{array}\right. \\
& y_{D 4}(x)=\left\{\begin{array}{cc}
0 \quad x \leq S_{3} \text { or } x \geq s_{5} \\
\frac{X-S_{3}}{S_{4}-S_{3}} & S_{3}<x<s_{4} \\
\frac{S_{5}-X}{S_{5}-S_{4}} & S_{4} \leq x<s_{5}
\end{array}\right. \\
& y_{D 5}(x)=\left\{\begin{array}{rl}
0 & x \leq s_{4} \\
\frac{x-s_{4}}{s_{5}-s_{4}} & s_{4}<x<s_{5} \\
1 & x \geq s_{5}
\end{array}\right.
\end{aligned}
$$


2) The membership function of a reverse index

According to the analysis of geologic park's health status, the membership function of inverse indicators can adopt the half-trapezoidal distribution function and the linear triangular function as follows:

$$
\begin{aligned}
& y_{D 1}(x)=\left\{\begin{array}{rl}
0 & x \leq s_{2} \\
\frac{x-s_{2}}{s_{1}-s_{2}} & s_{2}<x<s_{1} \\
1 & x \geq s_{1}
\end{array}\right. \\
& y_{D 2}(x)=\left\{\begin{array}{cc}
0 \quad x \geq & S_{1} \text { or } x \leq S_{3} \\
\frac{S_{1}-x}{S_{1}-S_{2}} & S_{2}<x \leq S_{1} \\
\frac{X-S_{3}}{S_{2}-S_{3}} & S_{3}<x<s_{2}
\end{array}\right. \\
& y_{D 3}(x)=\left\{\begin{array}{cc}
0 \quad x \leq S_{4} \text { or } x \geq S_{2} \\
\frac{S_{2}-X}{S_{2}-S_{3}} & S_{3}<x \leq S_{2} \\
\frac{X-S_{4}}{S_{3}-S_{4}} & S_{4}<x<S_{3}
\end{array}\right. \\
& y_{D 4}(x)=\left\{\begin{array}{cc}
0 \quad x \leq & S_{5} \text { or } x \geq S_{3} \\
\frac{S_{3}-X}{S_{3}-S_{4}} & S_{4}<x \leq S_{3} \\
\frac{X-S_{5}}{S_{4}-S_{5}} & S_{5}<x<S_{4}
\end{array}\right. \\
& y_{D 5}(x)=\left\{\begin{array}{rl}
0 & x \geq s_{4} \\
\frac{s_{4}-x}{s_{4}-s_{5}} & s_{5}<x<s_{4} \\
1 & x \leq s_{5}
\end{array}\right.
\end{aligned}
$$

where, $\mathrm{x}$ is the measured value of the evaluation index; $\mathrm{s} 1$ is the first level of the evaluation index (morbid) standard value; s2 is the second level of the evaluation index (general morbid) standard value; s3 is the third level of the evaluation index (Subhealthy); s4 is the fourth level (healthy) of the evaluation index; s5 is the fifth level (very healthy) of the evaluation index.

\section{The results of ecological health evaluation and empirical analysis}

\section{Membership matrix}

Combined with the standard values of Table 2 and the intragroup weights of each indicator obtained through the normalization method, the data of 2012-2016 are 
calculated by MATLAB 2010b software, and the membership matrix of the driving force indicator is obtained as follows:

$$
\begin{aligned}
& R_{D}^{2012}=\left[\begin{array}{lllll}
0 & 0.15 & 0.85 & 0 & 0 \\
0 & 0 & 0 & 0 & 1 \\
0 & 0 & 0 & 0 & 1
\end{array}\right] \\
& R_{D}^{2013}=\left[\begin{array}{lllll}
0 & 0 & 0.85 & 0.15 & 0 \\
0 & 0 & 0 & 0 & 1 \\
0 & 0 & 0 & 0 & 1
\end{array}\right] \\
& R_{D}^{2014}=\left[\begin{array}{lllll}
0 & 0 & 0.95 & 0.05 & 0 \\
0 & 0 & 0 & 0 & 1 \\
0 & 0 & 0 & 0 & 1
\end{array}\right] \\
& R_{D}^{2015}=\left[\begin{array}{lllll}
0 & 0.05 & 0.95 & 0 & 0 \\
1 & 0 & 0 & 0 & 0 \\
0 & 0 & 0 & 0 & 1
\end{array}\right] \\
& R_{D}^{2016}=\left[\begin{array}{lllll}
0 & 0 & 0.6 & 0.4 & 0 \\
0 & 0.58670 .41330 & 0 \\
0 & 0 & 0 & 0 & 1
\end{array}\right]
\end{aligned}
$$

Fuzzy comprehensive evaluation

$\mathrm{WD}=(0.3089,0.3613,0.3298)$

Thus, we can get the fuzzy evaluation result of driving force health degree from 2012 to 2016:

$$
\begin{aligned}
& H_{D}^{2012}=W_{D} \bullet R_{D}^{2012} \\
& =(0.3089,0.3613,0.3298) \bullet\left[\begin{array}{lllll}
0 & 0.15 & 0.85 & 0 & 0 \\
0 & 0 & 0 & 0 & 1 \\
0 & 0 & 0 & 0 & 1
\end{array}\right] \\
& =(0,0.0463,0.2626,0,0.6911)
\end{aligned}
$$




$$
\begin{aligned}
& H_{D}^{2013}=W_{D} \bullet R_{D}^{2013} \\
& =(0.3089,0.3613,0.3298) \bullet\left[\begin{array}{lllll}
0 & 0 & 0.85 & 0.15 & 0 \\
0 & 0 & 0 & 0 & 1 \\
0 & 0 & 0 & 0 & 1
\end{array}\right] \\
& =(0,0,0.2626,0.0463,0.6911) \\
& H_{D}^{2014}=W_{D} \bullet R_{D}^{2014} \\
& =(0.3089,0.3613,0.3298) \bullet\left[\begin{array}{lllll}
0 & 0 & 0.95 & 0.05 & 0 \\
0 & 0 & 0 & 0 & 1 \\
0 & 0 & 0 & 0 & 1
\end{array}\right] \\
& =(0,0,0.2935,0.0154,0.6911) \\
& H_{D}^{2015}=W_{D} \bullet R_{D}^{2015} \\
& \left.\qquad \begin{array}{lllll}
0 & 0.05 & 0.95 & 0 & 0 \\
1 & 0 & 0 & 0 & 0 \\
0 & 0 & 0 & 0 & 1
\end{array}\right] \\
& =(0.3089,0.3613,0.3298) \bullet[0.3613,0.0154,0.2935,0,0.3298) \\
&
\end{aligned}
$$

\section{Health index}

In this paper, we can get the result of comprehensive evaluation of driving force factor by using fuzzy centroid method, that is, the driving force factor health index is as follows (where cj takes the median of health score threshold, ie $\mathrm{c} 1=0.1, \mathrm{c} 2=0.3, \mathrm{c} 3=$ c5 = 0.9):

$$
\begin{aligned}
& C_{D}^{2012}=\sum_{j=1}^{5}\left(h_{j} c_{j}\right)=0.7672 \\
& C_{D}^{2013}=\sum_{j=1}^{5}\left(h_{j} c_{j}\right)=0.7857 \\
& C_{D}^{2014}=\sum_{j=1}^{5}\left(h_{j} c_{j}\right)=0.7795 \\
& C_{D}^{2015}=\sum_{j=1}^{5}\left(h_{j} c_{j}\right)=0.4843 \\
& C_{D}^{2016}=\sum_{j=1}^{5}\left(h_{j} c_{j}\right)=0.6143
\end{aligned}
$$


By the same token, we can calculate the stress, status, influence, response factors and the health index integrated in 2012-2016.

The stress factor health index is calculated as follows:

$$
\begin{aligned}
& C_{P}^{2012}=\sum_{j=1}^{5}\left(h_{j} c_{j}\right)=0.4326 \\
& C_{P}^{2013}=\sum_{j=1}^{5}\left(h_{j} c_{j}\right)=0.4956 \\
& C_{P}^{2014}=\sum_{j=1}^{5}\left(h_{j} c_{j}\right)=0.5296 \\
& C_{P}^{2015}=\sum_{j=1}^{5}\left(h_{j} c_{j}\right)=0.5169 \\
& C_{P}^{2016}=\sum_{j=1}^{5}\left(h_{j} c_{j}\right)=0.5672
\end{aligned}
$$

The state factor health index is calculated as follows:

$$
\begin{aligned}
& C_{S}^{2012}=\sum_{j=1}^{5}\left(h_{j} c_{j}\right)=0.6270 \\
& C_{S}^{2013}=\sum_{j=1}^{5}\left(h_{j} c_{j}\right)=0.5930 \\
& C_{S}^{2014}=\sum_{j=1}^{5}\left(h_{j} c_{j}\right)=0.5324 \\
& C_{S}^{2015}=\sum_{j=1}^{5}\left(h_{j} c_{j}\right)=0.5152 \\
& C_{S}^{2016}=\sum_{j=1}^{5}\left(h_{j} c_{j}\right)=0.5967
\end{aligned}
$$

The impact factor health index is calculated as follows:

$$
\begin{aligned}
& C_{I}^{2012}=\sum_{j=1}^{5}\left(h_{j} c_{j}\right)=0.7293 \\
& C_{I}^{2013}=\sum_{j=1}^{5}\left(h_{j} c_{j}\right)=0.7635
\end{aligned}
$$




$$
\begin{aligned}
& C_{I}^{2014}=\sum_{j=1}^{5}\left(h_{j} c_{j}\right)=0.7189 \\
& C_{I}^{2015}=\sum_{j=1}^{5}\left(h_{j} c_{j}\right)=0.7214 \\
& C_{I}^{2016}=\sum_{j=1}^{5}\left(h_{j} c_{j}\right)=0.7214
\end{aligned}
$$

The response factor health index is calculated as follows:

$$
\begin{aligned}
& C_{R}^{2012}=\sum_{j=1}^{5}\left(h_{j} c_{j}\right)=0.5546 \\
& C_{R}^{2013}=\sum_{j=1}^{5}\left(h_{j} c_{j}\right)=0.5958 \\
& C_{R}^{2014}=\sum_{j=1}^{5}\left(h_{j} c_{j}\right)=0.6097 \\
& C_{R}^{2015}=\sum_{j=1}^{5}\left(h_{j} c_{j}\right)=0.8109 \\
& C_{R}^{2016}=\sum_{j=1}^{5}\left(h_{j} c_{j}\right)=0.8273
\end{aligned}
$$

The general health index is calculated as follows:

$$
\begin{aligned}
& C^{2012}=\sum_{j=1}^{5}\left(h_{j} c_{j}\right)=0.6298 \\
& C^{2013}=\sum_{j=1}^{5}\left(h_{j} c_{j}\right)=0.6455 \\
& C^{2014}=\sum_{j=1}^{5}\left(h_{j} c_{j}\right)=0.6216 \\
& C^{2015}=\sum_{j=1}^{5}\left(h_{j} c_{j}\right)=0.6120
\end{aligned}
$$




$$
C^{2016}=\sum_{j=1}^{5}\left(h_{j} c_{j}\right)=0.6643
$$

\section{Results}

According to the results of the fuzzy comprehensive evaluation, the overall ecological health status of Xiaonanhai Geopark in 2012-2016 is "healthy", which is consistent with the reality of Xiao Nanhai scenic spot. The factors and indicators status analysis are as follows:

First, the "driving force" factors are all "healthy" except the "sub-healthy" state of 2015, but the score in 2015 and 2016 has dropped significantly. The economic benefits of Qianjiang Xiaonanhai Geopark generally show a downward trend. The natural growth rate of the local population is relatively high, which has a great burden on the environment. The growth rate of tourist numbers fluctuates from year to year shows even negative growth in 2015. This is also the main reason why the driving force declines in the score. The economic benefits brought by the geoparks are relatively limited. The driving force for economic growth and tourism development needs further improvement.

Second, the "stress" factor has been in a "sub-healthy" state (health degree: 0.43260.5672). However, due to the slowdown of the social and economic development in the "driving force" factor, the "stress" factor has a good development trend. The key indicators that have a negative effect on the "stress" factors are the "regional development index", "concentration of tourist space utilization" and "days of natural disasters". The method to balance the contradiction between the socio-economic benefits of the park and the pressure of the natural environment still needs to be further explored.

Third, the "state" factor is basically in a "sub-healthy" state except in "healthy" state in 2012. Due to the "stress" factor, the "state" factor tends to be "healthy" in 2016. However, the change of "pressure" factor is larger than that of "state" factor, which shows that the influence of "pressure" factor on the ecosystem health of Xiaonanhai scenic spot has some lag. According to the score, the overall state of the Xiaonanhai Geopark in Qianjiang is relatively stable, and the status of vegetation, biology and air quality are in a healthy state and above. However, the pollution status of surface water needs to be improved.

Fourth, affected by the "state" factor, the "impact" factor is basically in a "healthy" state (health: $0.7635-0.7214$ ). Overall tourist satisfaction has brought positive publicity to the scenic spots. However, because of the limitations of such factors as the landscape quality, the geographical location of the park and the incompleteness of the surrounding recreational facilities, the popularity and the exposure of the media is relatively low. To a certain extent, all these limited the further development of the park.

Fifthly, due to the good development of "influence" factor, "health" has been maintained. In the face of "sub-health" state of "stress" factor and "state factor" (Health: 0.5546) The status gradually improved to become "very healthy" (Health: 0.8273). The state of infrastructure in the park is intact. With increasing investment in infrastructure and environmental protection in the park, the government has also formulated more complete laws and regulations for the tourist attractions and improved the internal governance framework of the park. 
Sixthly, although the "stress" factor and the "status" factor have the threat of being "sub-health", the overall health status of the park has shown a "healthy" state in recent years, and the overall development trend is good. However, due to the obvious difference between the indicators, the key factors affecting the health of Qianjiang Xiaonanhai Geopark are also the focus of sustainable development in the future. The main focus is on the growth of tourist population, regional development index, tourist space utilization, and tourist popularity of these indicators. In short, the protection should be taken into account to ensure the healthy development of regional ecosystems without exploiting.

Compared with previous studies, this paper adopts fuzzy comprehensive evaluation method instead of the commonly used AHP method, which can more comprehensively evaluate the health level of geoparks; Moreover, because the health assessment methods are relatively new, no one has yet addressed special evaluation of the health of geoparks. Therefore, this paper has a strong innovation in the establishment of the evaluation index system for geoparks and the calculation methods.

Figure 2 shows the 2012-2016 overall condition of factors and comprehensive score trends of the Qianjiang Xiaonanhai Geopark.

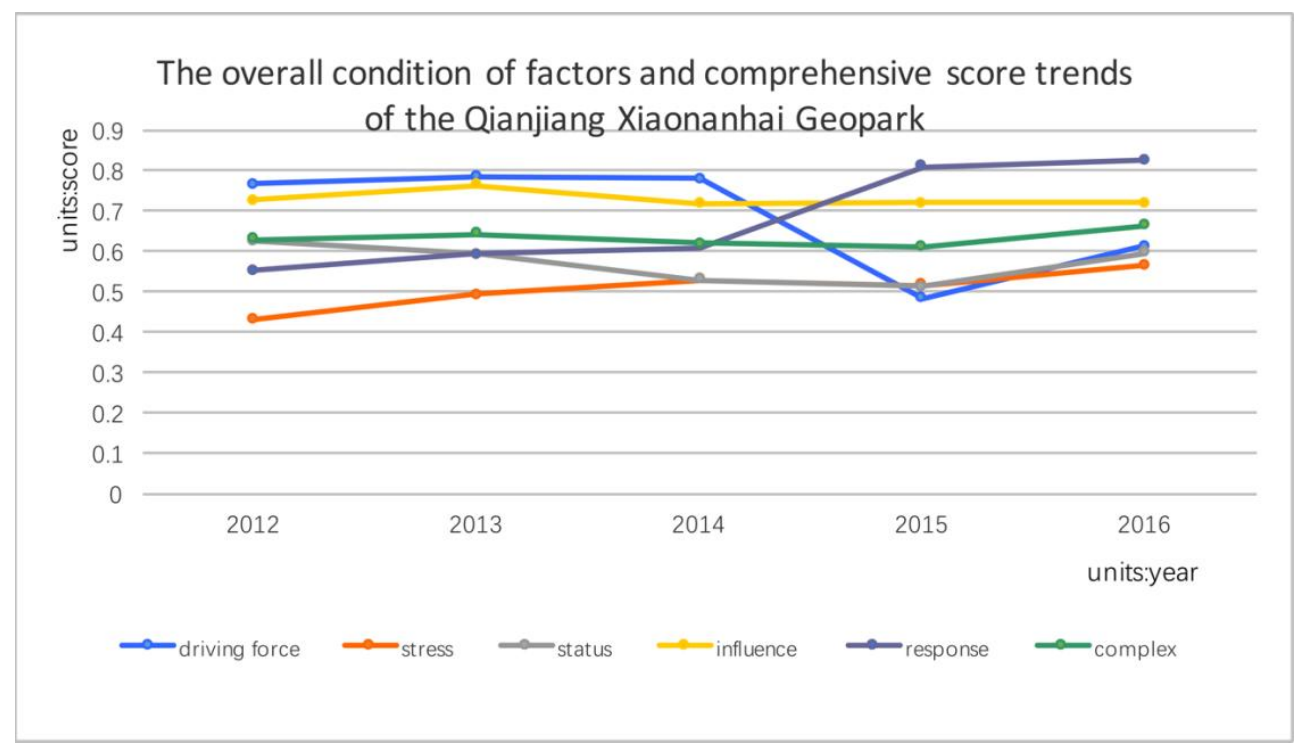

Figure 2. The overall condition of factors and comprehensive score trends of the Qianjiang Xiaonanhai Geopark

\section{The protection and countermeasures of development}

The Qianjiang Xiaonanhai Geopark has developed steadily in recent years, and the overall ecological health level is "healthy", but some indicators are too low, reflecting the obvious shortcomings in the construction and development of the geopark. Based on the results of empirical analysis and field investigation, we propose the following countermeasures and suggestions for Xiaonanhai Geopark: 
Improve the mechanism of talent introducing and the overall quality and management level of employees

The development of the Xiaonanhai Geopark needs leaders with long-term development strategic vision and a group of managers with the rich professional knowledge to undertake the important task of protecting geological relics. The duties of all staff positions should be cleared. The assessment system should be formulated, and all aspects should be introduced to professionals. They can provide professional guidance for the construction of geoparks based on the needs of the park.

Establish Qianjiang Xiaonanhai Geopark Museum, improve public facilities within the park, and further carry out popular science education, geological teaching and geological heritage tourism

At present, the science popularization facilities in Xiaonanhai Geopark are still in a backward state. We should further speed up the construction of popular science museums in the park, improve the design and the layout of geological knowledge explaining cards, equip the park with the corresponding geo-knowledge voice explaining equipment, give full play to the characteristics of science popularization in geological parks, set up a tourism network that takes science tourism as the leading role and build boutique tourism route.

Organize the implementation of funds, speed up the construction of key scenic spots and improve the surrounding facilities

Due to funding constraints, the process of Xiaonanhai Geopark internal construction is extremely slow. At present, the level of the key scenic spots construction in the Xiaonanhai Geopark is very low, and tourists have a very poor view. There are almost no matching facilities around the scenic spots and the tour process is extremely inconvenient. On the one hand, sources of funds can seek the support of national policies; on the other hand, the park can set up the Qianjiang Xiaonanhai Geopark Sustainable Development Fund, accepting donations and financing from all walks of life to provide the material guarantee for the internal construction of scenic spots.

Cooperate with scientific research organizations of universities, formulate scientific and feasible scientific research plans so that the sites can be scientifically protected and developed

The site of Xiaonanhai Geopark has great scientific value and potential for scientific research, and its future research should attract the attention of scientific research organizations in relevant disciplines. Xiaonanghai Geopark can cooperate with the organizations of universities and colleges in the relevant disciplines, regularly repair and reinforce the sites and formulate a series of scientific and feasible scientific research plans so as to protect better and scientifically utilize the precious relic resources.

Organize high-quality science popularization activities in geosciences, improve foreign media window and the public and media exposure and enhance the scenic spot popularity

The small amount of tourists in the Xiaonanhai geological park, to a large extent, is caused by the low popularity of the scenic spot. Geoparks can regularly organize activities of science popularization to increase the public interaction rate. At the same 
time, the park can establish and improve self-media platforms such as Weibo, official account of wechat and websites of scenic spots so as to improve the amout of information output and radiate influence and enhance the visibility of scenic spots.

Plan scenic spot development, improve space utilization efficiency and further improve the management system

At present, the interior planning of the Xiaonanhai Geopark is rather chaotic. There are 7 major programs in Xiaonanhai such as scenic spot planning, holiday area planning and nature reserve planning. The plans do not converge with each other. Therefore, the park planning and implementation are difficult. There should be a unified planning and layout designing of the Xiaoganhai Geopark, and a further improvement of the park's internal management system should be implemented, such as implementing the smooth management to avoid the restriction of various departments so as to enhance the efficiency of planning and implementation.

Based on the predecessors' ecological health theory, we compared most of the existing research index system evaluations to a large industry, such as tourism, and there is no specific evaluation index system for specific environments. There is very little research on a new concept, and we have constructed an ecological health assessment index system based on the DPSIR conceptual model specifically for geoparks, which makes up for the gap in this area to a certain degree, aiming at future generations to address the health of geoparks. The degree study provides reference. It has a high degree of innovation and uses Minjiang Xiaonanhai Park as a specific case. It proposes an evaluation method for the ecological health index of geopark tourist areas based on fuzzy mathematics and shows how to evaluate the ecology of the target area. The complete process of health puts forward scientific countermeasures and suggestions according to local conditions, which has high practical value and responds to the call of green tourism and is conducive to sustainable development.

\section{Discussion}

Based on the theory of ecological health, this paper takes Chongqing Xiaojianghai Xiaonanhai Geopark as an example. Based on the DPSIR conceptual model, an ecological health index evaluation system suitable for geoparks is constructed. The weights are confirmed by entropy weight method and multilevel fuzzy synthesis is used. The evaluation method calculates the ecological health degree of the geopark and concludes that the comprehensive health index of the park in the past five years is in a generally healthy state. The results show that the highest score of Qianjiang Xiaonanhai Geopark is 0.6643, and the lowest score is 0.6120. Based on local conditions, reasonable suggestions are proposed for the sustainable development of the Qianjiang Xiaonanhai Geopark.

Based on the predecessors' ecological health theory, compared with most of the existing research index system evaluations to a large industry, such as tourism, we found that there is no specific evaluation index system for specific environments. There is very little research on a health degree, and we have constructed an ecological health assessment index system based on the dpsir conceptual model specifically for geoparks, which makes up for the gap in this area to a certain degree, aiming at future generations to address the health of geoparks. The degree study provides future reference and has a high degree of innovation. It proposes an evaluation method for the ecological health 
index of geopark tourist areas based on fuzzy mathematics, and shows the complete process of how to evaluate the ecology of the health degree of a target area. Moreover, it can put forward scientific countermeasures and suggestions according to local conditions, which have high practical value. This research responds to the call of green tourism, which is conducive to sustainable development.

\section{Conclusion}

Ecological health and its evaluation are a very new and constantly updating field and ecological health of tourism areas is a new research direction. The development and protection of geopark tourism areas is a hot topic in current tourism industry. This article introduces the concept of a comprehensive assessment of health, and it is a groundbreaking and exploratory work in the geopark tourist area. However, due to time and energy and data acquisition reasons, there are still some fields worth deep study:

First, the size of sample on the study should be increased and a more detailed investigation and analysis should be done. More common conclusions could be drawn and further improvement of the construction of index evaluation system could be implemented.

Second, further follow-up research should be carried out, through longer-term data tracking and analysis, to understand the relevant factors and mechanisms of ecosystem health, and to select the same type of tourist areas at different stages of development for comparative research. Different tourism development stages should be compared and continuously study on the impact of ecological health.

Third, the concept of ecological health assessment could be applied to other areas and the research could be further expanded. The cross-contrast between different industries should be enhanced and the conceptual connotation of the research field should be enriched.

\section{REFERENCES}

[1] Edoardo, A. C., Costantini, L. A. (1986):The river cultural heritage of Italy: Geodata-base, maps, and pedodiversity evaluation. - Annals of Tourism Research 1: 11-35.

[2] Li, X. (2012): Research on the ecological health diagnosis and regulation of mountain tourist areas based on DPSIR conceptual model. - Yunnan University.

[3] Order No. 77 of the Ministry of Land and Resources of the People's Republic of China (2000).

[4] Peng, J., Wang, Y., Wu, J., Zhang, Y. (2007): Regional Ecosystem Health Evaluation Research Methods and Progress. - Chinese Journal of Ecology (11): 4877-4885.

[5] Qian, L., Zhao, S. (2006): Research on sustainable development model of geological park based on geological relics-taking Wudalianchi Global Geopark as an example. Resource Development \& Market 5(6):557-560.

[6] Qin, Q., Dai, W., Liu, X. (2013): Health evaluation of constructed wetland ecosystems in urban area of Wumeng Mountain: A case study of Liupanshui Lake National Wetland Park. - Journal of Hydroecology 34(5): 43-46.

[7] Qin, X., Lu, X. (2014): Study on Mechanism and System Simulation of Ecological Security in Coastal Cities. - Chinese Population, Resources and Environment 24(2): 6068. 
[8] Shi, S., Chen, Q. (2015): Evaluation of Ecological Civilization Construction in Fujian Province Based on DPSIR Model. - Journal of Fujian Agriculture and Forestry University (Philosophy and Social Science Edition) 18(5): 45-51.

[9] Wandersee, J. H., Clary, R. M. (2005):Case Studies of Two American Towns That Have Re-cently Developed Geotourism Venues: A Comparison of Steps Taken inGeoscience EducationProgramDevelopment.EosTrans.AGU,86(52),FallMeet.Suppl .UR:hettp://www .earhscholars.com/.2005,79(5B):168-71.

[10] Wang, J. (2016): Study on the evaluation of the health of tourism industry in China. Xiangtan University.

[11] Xie, H., Liu, H. (2003): Geological Tourism Features and Reference in American National Parks. - Karst China 22(1): 73-76.

[12] Yang, L., Wang, J., Huang, H. (2008): Dongxi Watershed Ecosystem Health Assessment Based on PSR Framework Model. - Resource Science, 107-113.

[13] Yue, F., Liu, C. (2008): Financial evaluation of agricultural institutions based on fuzzy analysis. - Journal of Qilu University of Technology(Natural Science) 22(3): 53-56.

[14] Zhao, S., Chai, L., Li, P., Cheng, H. (2013): New Model of Urban Ecosystem Health Assessment and Its Application: A Case Study of Tianjin 117 City. - Journal of Environmental Science, 1173-1179.

[15] Zhu, F. (2014): Study on the Evaluation of New Urbanization Development Level in Heilongjiang Province. - Harbin University of Science and Technology.

[16] Zhu, J., Tang, Z., Liu, X. (2012): Evaluation of Low-carbon City Development Based on DPSIR Model: A Case Study of Jiyuan City. - Urban Issues, 42-47.

[17] Zhu, W., Guo, Y., Sun, P. (2012): Wetland ecosystem health evaluation in the lower reaches of Tumen River. - Chinese Journal of Ecology 32(21): 6609-6618. 